\title{
HYDRODYNAMIC EFFECTS OF DRILL HOLES ON POSTMORTEM TRANSPORTATION OF BIVALVE SHELLS AND ITS TAPHONOMIC IMPLICATIONS
}

\author{
DEVAPRIYA CHATTOPADHYAY, ${ }^{1}$ ASHISH RATHIE, ${ }^{1}$ DANIEL J. MILLER,${ }^{2}$ AND TOMASZ K. BAUMILLER ${ }^{2}$ \\ ${ }^{1}$ Indian Institute of Science Education and Research Kolkata, Department of Earth Sciences, Mohanpur, WB-741252, India \\ ${ }^{2}$ University of Michigan, Museum of Paleontology, 1109 Geddes, Ann Arbor, Michigan 48109-1079, U.S.A. \\ e-mail: devapriya@iiserkol.ac.in
}

\begin{abstract}
Predatory drill holes in marine invertebrates are an important source of information on the nature of biotic interactions and are often used to explore the ecological and evolutionary roles of such interactions in deep time. Measures of drilling frequencies and drill-hole site stereotypy represent the raw data for inferring the intensity and selectivity of drilling predation. One potential source of bias explored in this study relates to the hydrodynamic properties of shells: presence of drill holes and/or drill-hole position may influence how shells behave when subjected to moving fluids. In a unidirectional flowtank study with the bivalve Donax scortum Linnaeus, 1758, we found that the threshold current velocity for the entrainment of undrilled convex-up shells is significantly lower than for centrally drilled shells, which could be explained by Bernoulli's principle. The position of the drill hole on a shell also affects its hydrodynamic properties because umbonally drilled shells require a lower entrainment velocity than centrally drilled shells. This difference could potentially result in assemblages of different stereotypic patterns. We also demonstrate the extent of alteration of an assemblage by this process using a simulation parameterized with experimental results. The latter show that a dramatic change in inferred drilling intensity, size selectivity, and stereotypic patterns from the original population can be produced by hydrodynamic sorting. Our study indicates that such sorting can yield a sample significantly different from the original one in terms of drill-hole characteristics. Hence, the effect of such bias should be assessed before inferring the nature of biotic interaction of fossil assemblages.
\end{abstract}

\section{INTRODUCTION}

The traces of predation made by drilling gastropods represent an important source of information on the nature of biotic interactions and have often been used to explore the ecological and evolutionary roles of such interactions. The drill-hole shape is used for recognizing the identity of a predator; two families of extant predatory gastropods, naticids and muricids, produce drill holes that are easily distinguishable (Carriker and Yochelson 1968). Drill holes are used to quantify various aspects of biotic interactions because drilled shells are commonly preserved in the fossil record (Hoffman et al. 1974; Hoffman 1976; Taylor et al. 1983; Vermeij 1983, 1987; Kelley 1989, 1991; Anderson 1992; Kowalewski et al. 1998; see Kelley and Hansen 2003 for review). For example, the frequency of drill holes has been used to estimate predation intensity (e.g., Taylor 1970; Stanton and Nelson 1980; Vermeij et al. 1980; Vermeij and Dudley 1982; Kabat and Kohn 1986; Vermeij 1987; Kowalewski et al. 1998; Chattopadhyay 2011; Chattopadhyay and Dutta 2013), whereas the consistency of drill-hole placement on prey shells (drill-hole stereotypy) and the correspondence of drill holes to internal anatomy have been used to infer important information about predatory behavior (Kelley and Hansen 2003 and references therein). The tacit assumption of these studies is that patterns of drilling are not altered by taphonomic processes. Numerous studies, however, have cautioned that a number of effects can mask the true boring intensity and lead to misinterpretation of the paleoecology of an assemblage (De Cauwer 1985; Velbel and Brandt 1989; Harper et al. 1998). These effects include the differential resistance of valves to taphonomic forces before or after burial, the destruction of valves by nondrilling durophages, and the sorting of valves by currents or other agents. For example, Roy et al. (1994) found a significant difference in strength between drilled and undrilled Mulinia valves; the bored ones are weaker under point load compression. This bias only appears to affect shells in high-energy environments (Hagstrom 1996), however, and may not be produced by natural sediment compaction (Zuschin and Stanton 2001; Kelley 2008). Differences in shape and/or thickness might also lead to an unequal preservation probability (Velbel and Brandt 1989). Such preferential removal of a particular valve might alter the original drilling frequency (Kaplan and Baumiller 2000). Note that such sorting would affect drilling frequency only if one valve was preferentially drilled, which is not normally the case for equivalved taxa (e.g., Kelley 1982) but may occur for inequivalved taxa, such as corbulids (e.g., De Cauwer 1985; Kelley 1988; Kardon 1998). A slightly different type of bias that affects such frequency could be produced when valves with only complete margins are considered for calculating drilling frequency (Klompmaker 2009). A biased drilling frequency could also result from the destruction of valves by nondrilling durophagous predators (Vermeij et al. 1989).

The effect of fluid movement on a shell assemblage can also introduce a bias due to differential sorting. Numerous studies have examined current competencies required to reorient brachiopod shells, as well as the subsequent alignment of shells following transport (Menard and Boucot 1951; Johnson 1958; Kornicker and Armstrong 1959; Nagle 1967; Alexander 1975, 1984, 1986; LaBarbera 1977; Savarese 1994; Quaresma 
et al. 2007). Menard and Boucot (1951) observed that shape, size, effective density, and ornamentation influence the competent velocity of brachiopod shells. When subjected to wave and current action, shells with a range of these properties would be differentially affected resulting in substantial differences between transported and untransported assemblages (Boucot 1953). Boucot et al. (1958) described a statistical method for helping to identify such effects. Messina and LaBarbera (2004), however, found no significant difference in entrainment velocities of brachiopod shells of different size and shape. Nonetheless, they attributed such lack of correlation between critical velocity and shell parameters to the high variability of velocity for a single specimen and a relatively small range of sizes of the brachiopod specimens used in their experiments.

A number of detailed studies have evaluated the effect of shape, size, initial orientation, and grain size of the associated sediments on entrainment velocity of bivalve shells (Brenchley and Newall 1970; Trewin and Welsh 1972; Futterer 1982; Allen 1984; McKittrick 1987; Frey and Dörjes 1988; Olivera and Wood 1997; Chattopadhyay et al. 2013); these experiments have shown that differences in these characteristics could alter the overall distribution of an assemblage by preferential removal of a particular group of shells (e.g., size class, shape class, taxa).

The minor differences between right and left valve geometry of bivalve shells could also affect their hydrodynamic behavior. A study by MartinKaye (1951) showed that postmortem transport by waves of bivalve shells could result in a differential distribution of right and left valves, even though the two valves of the bivalve Pitar dione are identical except that one is the mirror image of the other. Boucot et al. (1958) predicted that asymmetric shells would tend to diverge dextrally and sinistrally from the direction of the current and therefore result in a sorted assemblage. Similar phenomena have been reported in other studies (Lever 1958; Kornicker et al. 1963; Nagle 1964; Lever and Thijssen 1968; Behrens and Watson 1969; Frey and Henderson 1987). More recently, such an effect was demonstrated using a statistical model based on experimental results of undrilled shell transport (Chattopadhyay et al. 2013). If predators were to preferentially drill one of the valves, hydrodynamic transport would alter the true drilling frequency, based on the results of these studies.

Drilling frequencies could also be altered if the hydrodynamics of shells are affected by the presence/absence of a drill hole itself. Lever et al. (1961), in a mark and recapture experiment, demonstrated that drilled and undrilled valves exhibit different hydrodynamic behavior. They found that umbonally drilled valves were carried higher onto the beach compared with undrilled shells. That study, however, lacked experimental determination of entrainment velocities; such experiments have since been conducted and have confirmed that drilled and undrilled valves have different entrainment velocities (Miller 1991; Chattopadhyay et al. 2006). Here, the differences in entrainment velocities between drilled and undrilled shells are quantified experimentally, and these results are used in computer simulations to explore their potential for altering assemblages in terms of drilling frequency, prey size preference, and stereotypy.

\section{Conceptual Model}

Disarticulated Shells in Flow.-The hydrodynamics of a shell submerged in moving fluid have been discussed in earlier papers (Olivera and Wood 1997; Chattopadhyay et al. 2013). In the most general form they can be summarized as follows. The two main fluid forces that act on a shell in a moving fluid are drag, acting parallel to the direction of the flow, and lift, acting perpendicular to flow. The expression for the force of drag is

$$
F_{\text {drag }}=1 / 2 C_{d} \times \rho_{\text {fluid }} \times U^{2} L^{2}
$$

whereas that for the force of lift is

$$
F_{\text {lift }}=1 / 2 C_{1} \times \rho_{\text {fluid }} \times U^{2} L^{2}
$$

where $\rho_{\text {fluid }}$ is the density of the fluid; $U$ is fluid velocity; $L^{2}$ is area of the object, perpendicular to flow in the case of drag and parallel to flow in the case of lift; and $C_{d}$ and $C_{1}$ are empirically derived coefficients of drag and lift, respectively. Because drag and lift can be considered destabilizing forces, whereas weight and friction are stabilizing forces, the stability of a shell in flow depends on the magnitude of drag and lift generated by the fluid, in relation to friction and gravity (Pena et al. 2008). The net vertical force acting on a shell is the sum of the downward-acting gravitational force and the upward-acting buoyancy and lift forces. This can be expressed as follows:

$$
F_{\text {down }}=V\left(\rho_{\text {shell }}-\rho_{\text {fluid }}\right) g-F_{\text {lift }}
$$

where $V$ is the volume of the object, $\rho_{\text {shell }}$ is its average density, $g$ is the gravitational constant, and the other terms are as above. If the magnitude of this net force is downward, the stabilizing frictional force is the product of this force and the coefficient of static friction, such that

$$
F_{\text {friction }}=C_{\text {friction }} \times F_{\text {down }}
$$

When the magnitude of the drag force produced by the moving fluid exceeds the stabilizing frictional force $\left(F_{\text {drag }}>F_{\text {friction }}\right)$ the shell becomes unstable; we refer to the velocity at which this occurs as the entrainment velocity $\left(U_{\text {entrainment }}\right)$.

Exploration of the general relationship between the size (mass) of the disarticulated shell lying convex up on the seafloor and entrainment velocity $\left(U_{\text {entrainment }}\right)$ using a scaling argument is possible with the defined equations. Assuming no change in shape with size (isometry) and a hydrodynamic regime Re (Reynolds number) in the range of $10^{3}$ to $10^{4}$, the coefficients of drag $\left(C_{\text {drag }}\right)$, lift $\left(C_{\text {lift }}\right)$, and friction $\left(C_{\text {friction }}\right)$ will be constant, or nearly so. If the density of the shell $\left(\rho_{\text {shell }}\right)$ and fluid $\left(\rho_{\text {fluid }}\right)$ are also constant, the stabilizing force will be proportional to the shell mass $(M)$, while the destabilizing forces of lift and drag will be proportional to the projected surface area of the shell $(A)$ (perpendicular to flow in the case of drag and parallel to flow in the case of lift) and velocity $(U)$. The stability threshold is reached when the stabilizing and destabilizing forces are equivalent such that

$$
M \infty A \times U_{\text {entrainment }}^{2}
$$

and because $A$ is proportional to $M^{2 / 3}$, again assuming isometry, the expected relationship between shell mass and velocity is

$$
U_{\text {entrainment }} \infty M^{1 / 6}
$$

In other words, one expects a positive but weak (exponent $\sim 0.17$ ) dependence of entrainment velocity on mass.

Shells with Drill Holes.-The magnitude of the drag and lift forces will depend on fluid velocity, its density, and the size, shape, and orientation of the shell. If a shell is concavoconvex, lies on the substrate in a convexup orientation, and flow is laminar, lift is produced due to a crowding of streamlines on the top of the shell. This produces a zone of relatively higher velocity above the shell and, according to Bernoulli's principle, lowers pressure in the fluid in that zone (Kornicker and Armstrong 1959; Vogel 1994). The region beneath or within the shell would experience very low or no velocity and, again according to Bernoulli's principle, higher pressure. The difference in pressure between the top and bottom of the shell produces lift on the shell, reduces the stabilizing frictional force, and, if the drag force is sufficient, leads to destabilization and entrainment (Fig. 1A). 

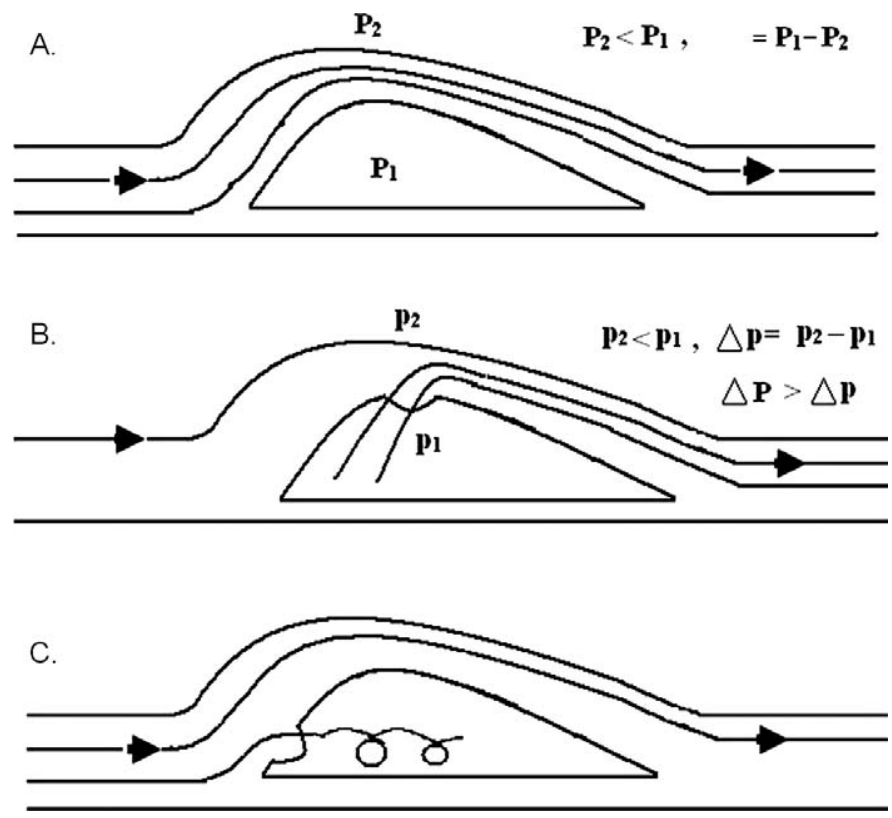

FIG. 1.-Schematic diagram showing the different patterns of fluid flow on a single valve of a disarticulated shell submerged in flowing fluid when $\mathbf{A}$ ) the valve has no drill hole (P represents pressure), B) the valve has a centrally located drill hole ( $\mathrm{p}$ represents pressure), or $\mathbf{C}$ ) the valve has an umbonally located drill hole.

When considering the scenario described earlier for shells that are drilled (Fig. 1B), the pressure gradient between the inside and outside of the shell may be affected by the presence of the drill hole. The hole on the top of the shell may lead to the exchange of fluid (leakage) between the inside and outside of the shell. As a result, the pressure difference (and, therefore, the resulting lift force) would be lower for a drilled than for an undrilled shell. Theoretically, destabilization of a shell with a hole should be more difficult, and one may predict that the entrainment velocity for an undrilled shell will be lower than a comparable shell with a drill hole. This type of an effect was demonstrated experimentally by Telford (1981, 1983) for Mellita quinquiesperforata, a cambered sand dollar with five or six slitlike holes (lunules) piercing its test. Telford (1983) showed that specimens of $M$. quinquiesperforata in which the lunules had been filled became destabilized at $\sim 15 \%$ lower velocities than those in which the lunules were open.

Although theoretical predictions about the behavior of shells in moving fluids are a powerful tool and have been used successfully (Christensen 1981; Dey 2003; Olivera and Wood 1997), there are many variables that may influence flow in subtle ways; hence, predictions based on hydrodynamic principles require experimental testing. The results of such experiments can be used to explore how the bias may affect the resulting assemblages; such an approach has not been pursued in previous studies (Lever et al. 1961; Miller 1991; Chattopadhyay et al. 2006). In this study, we experimentally evaluate the hydrodynamic behavior of shells as they increase in size and compare the behavior of drilled and undrilled shells using the bivalve species Donax scortum. Using precise experimental data on entrainment velocity and direction of movement, we also develop a quantitative simulation to evaluate the effect of such factors on overall distribution of shells after postmortem transportation.

\section{MATERIALS AND METHODS}

\section{Specimens}

Bulk samples of freshly disarticulated shells of D. scortum were collected from the foreshore beach environment of Chandipur-on-sea, Odissa, India. Samples contained drilled (centrally and umbonally) and undrilled valves (Fig. 2). Drill holes were all countersunk, which indicates that they were most likely produced by naticids (Carriker and Yochelson 1968). This is also supported by field observations that reveal the fauna to be dominated by naticids at this locality (D Chattopadhyay, personal observations, 2011, 2012). The size of the drill holes ranged from 0.4 to $4.0 \mathrm{~mm}$. Only shells that did not show any other visible damage were used. The mass of the dry valves was measured using an electronic balance $( \pm 0.001 \mathrm{~g})$. Anterior-posterior length (L) was measured for each valve using electronic slide calipers $( \pm 0.01 \mathrm{~mm})$. A total of 115 disarticulated valves were used for the experiment (Table 1).

\section{Experimental Protocol}

Experiments were conducted in a closed-circuit laboratory flume housed in the Fluvial Mechanics Laboratory of the Indian Statistical Institute, Calcutta. The dimension of the flume is $10 \mathrm{~m}$ by $50 \mathrm{~cm}$ by $50 \mathrm{~cm}$.
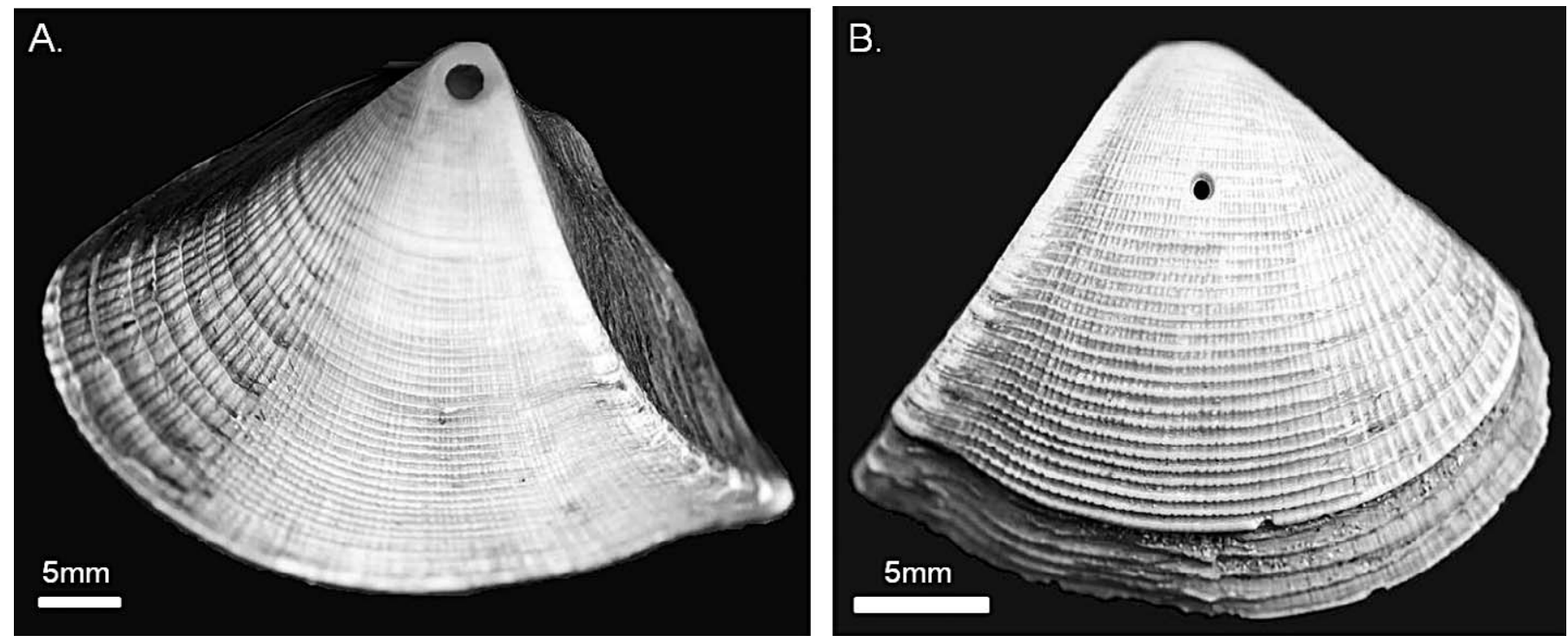

FIG. 2.-Donax scortum valves with drill holes. A) Shell with umbonally located drill hole. B) Shell with centrally located drill hole. 
TABLE 1.- Number, average size, and average mass of specimens in each category used in the present study.

\begin{tabular}{|c|c|c|c|c|c|c|}
\hline & & & \multicolumn{4}{|c|}{ Drilled } \\
\hline & \multicolumn{2}{|c|}{ Undrilled } & \multicolumn{2}{|c|}{ Umbonally } & \multicolumn{2}{|c|}{ Centrally } \\
\hline & Left & Right & Left & Right & Left & Right \\
\hline Number of specimens & 23 & 25 & 22 & 24 & 10 & 11 \\
\hline Mean size $(\mathrm{mm})$ & 41.23 & 39.68 & 39.41 & 39.51 & 39.8 & 39.37 \\
\hline Mean mass (g) & 3.53 & 3.166 & 2.27 & 2.3 & 2.51 & 2.19 \\
\hline
\end{tabular}

The flume bottom is made up of a 2-mm-thick flat-lying fiber sheet. The detailed design of the flume is discussed in Mazumder et al. (2005). The general protocol of the experiment is discussed in detail in Chattopadhyay et al. (2013). Here we present a brief summary.

Entrainment velocity measurements were conducted on 115 valves (48 undrilled, 21 centrally drilled, and 46 umbonally drilled; Table 1). Each valve was placed in still water on a glass plate in the flow tank with the umbo facing upstream. This was found to be the most stable configuration; the shells reoriented themselves if positioned differently. We chose glass rather than sediment because the frictional forces that stabilize the shell will vary with media (sediment grain size, sorting, cohesiveness, etc.) and are likely to change dynamically as sediment shifts during flow. The use of glass permits us to minimize variation in frictional forces and focus on the influence of the drill hole. Each run was conducted by gradually increasing flow velocity until the valve started to move continuously. That specific flow velocity was measured using a three-dimensional Micro-Acoustic Doppler Velocimeter (ADV) at a depth of $4 \mathrm{~mm}$ above the fiber sheet. For each specimen, entrainment velocity was measured three times.

\section{Simulation to Evaluate Final Distribution}

The detailed hydrodynamic behavior of a shell, although important, does not convey the full essence of the consequence unless we quantify the effect of such transport on the final assemblage. We therefore designed a computer simulation to evaluate the affected assemblages of $D$. scortum shells in unidirectional flow using the experimental results. We also analyzed the character of altered assemblages and how different they are from the original one.

We started with a population of 116,000 data points that represented $D$. scortum valves of various lengths. There are 96,000 data points that represent undrilled shells, while the rest were drilled. Among the drilled shells, the number of umbonally drilled valves was equal to centrally drilled valves. The population was normally distributed in terms of valve mass and characteristics of the mass distribution (range, mean, standard deviation) are comparable to the population used in the flow-tank experiments. Each data point had a drill-hole character (absence, central, umbonal), a size and mass value, and a corresponding entrainment velocity (EV). The values of EV were assigned based on the experimental results. The original shell population was subjected to a specific flow velocity (FV). At a particular velocity, the valves would get transported only if their entrainment velocity was less than the flow velocity $(\mathrm{EV} \leq \mathrm{FV})$.

Flow velocity was initially assigned the minimum EV value of the data set. This value of $\mathrm{FV}$ was compared with $\mathrm{EV}$ for each data point, and we tabulated the outcome in two categories: transported and lag. In the transported category we considered data points for which $\mathrm{EV} \leq \mathrm{FV}$, while the rest of the data points represent the lag category of that specific FV. For a specific FV, the following indices for both transported and lag categories were calculated: (1) drilling frequency (DF), (2) mean prey size, (3) variance in prey size, and (4) degree of drill-hole site stereotypy (DS).
These parameters were also calculated for the original population of 116,000 data points as original value.

All the data points in the simulation represent disarticulated valves; hence the frequency of drilling predation was calculated by dividing the number of drilled valves by half the total number of valves in the collection (Kowalewski 2002). Degree of site stereotypy was calculated by dividing the number of centrally drilled valves by the total number of drilled valves:

$$
\begin{aligned}
& \mathrm{DF}=N_{D} /(N \times 0.5) \\
& \mathrm{DS}=N_{C} / N_{D}
\end{aligned}
$$

where $N_{D}=$ Number of valves with drill hole;

$N_{C}=$ Number of valves with centrally located drill hole;

$N=$ Total number of valves.

Mean and variance of the prey size were calculated using the drilled (central and umbonal) population for each category. With every unit increment in $\mathrm{FV}$, the process was repeated. Finally, parameters (A through D) were compared between the original and altered assemblage (transported, lag) for a range of velocities using a one sample $t$-test. We used Microsoft Excel for creating this simulation, and the statistical analyses were done with PAST (Hammer et al. 2001).

\section{RESULTS \\ Length and Mass}

A significant positive correlation (Fig. 3) exists between the length and the mass of the D. scortum shells (Spearman's product moment correlation). This relationship is true for both undrilled specimens $(\rho=$ $0.99, \mathrm{p}<0.0001)$ and drilled specimens $(\rho=0.99, \mathrm{p}<0.0001)$. The masses of right and left valves in each category are comparable with each other (Mann-Whitney test; undrilled, $U=0.272, \mathrm{p}=0.75$; centrally drilled, $U=53, \mathrm{p}=0.91$; umbonally drilled, $U=264, \mathrm{p}=0.99)$. The undrilled shells are slightly heavier compared with drilled specimens. The difference between the means, however, is not statistically significant (Mann-Whitney test; centrally drilled, $U=426, \mathrm{p}=0.31$; umbonally drilled, $U=1029, \mathrm{p}=0.57$ ).

\section{Effect of Mass}

The entrainment velocity of a shell should be weakly dependent on mass if shells exhibit isometry, and scale as shell mass to $\sim 1 / 6(0.17)$ power. To test this prediction, a power function was fit to experimental results for all shells, undrilled, and umbonally and centrally drilled (Fig 4). The best-fit line has an exponent of 0.19 (95\% confidence interval [CI]: 0.14 to 0.24$)$ indicating that the relationship is significant and that the null hypothesis $\left(H_{0}: b=0.17\right)$ cannot be rejected $(\mathrm{p}<0.05)$. When the analysis is applied to undrilled and umbonally and centrally drilled shells independently, the relationship is significant in all instances and the exponents are 0.22 (95\% CI: 0.17 to 0.27 ) for undrilled, 0.16 (95\% CI: 0.09 to 0.23 ) for umbonally drilled, and 0.17 (95\% CI: 0.22 to 0.23 ) for centrally drilled shells (Fig. 4B-D), in good agreement with the theoretically predicted value of 0.17 .

\section{Effect of Drill Holes}

The effect of drill holes on entrainment velocity was evaluated by comparing the best-fit lines to the $\log -\log$ transformed data for undrilled, umbonally drilled, and centrally drilled shells (Fig. 5). Equations describing the best-fit lines are of the form $\ln M=\ln a+b \ln U_{\text {entrainment, }}$ equivalent to $M=a A\left(U_{\text {entrainment }}\right)^{b}$. As stated above, the exponents, $b$, for the three categories of shells are statistically indistinguishable from each other $\left(H_{0}: b_{\text {undrilled }}=b_{\text {umbonal }}=b_{\text {central }} ; \mathrm{p}=0.20 ; F\right.$-test $)$, indicating 


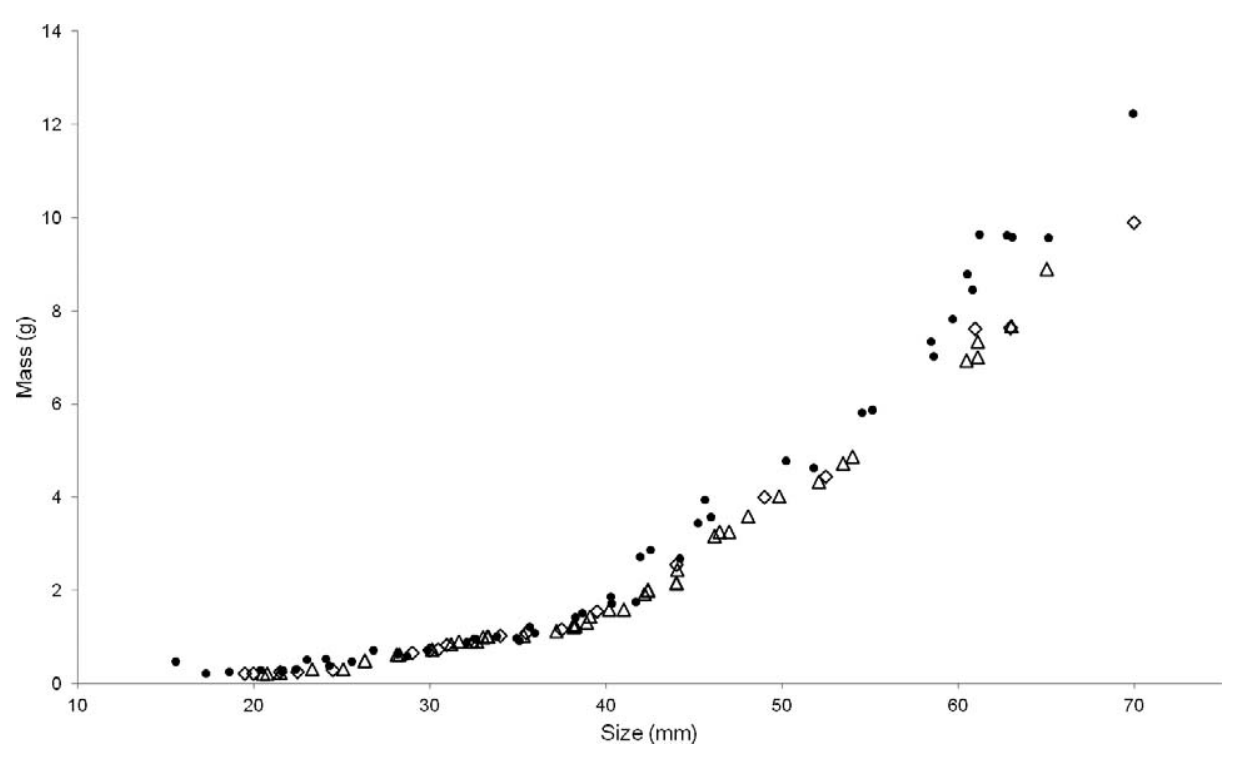

FIG. 3.-The relationship between size and mass for Donax scortum valves. Solid circle $=$ undrilled, open triangle $=$ umbonally drilled shells, open rhomb $=$ centrally drilled shells.
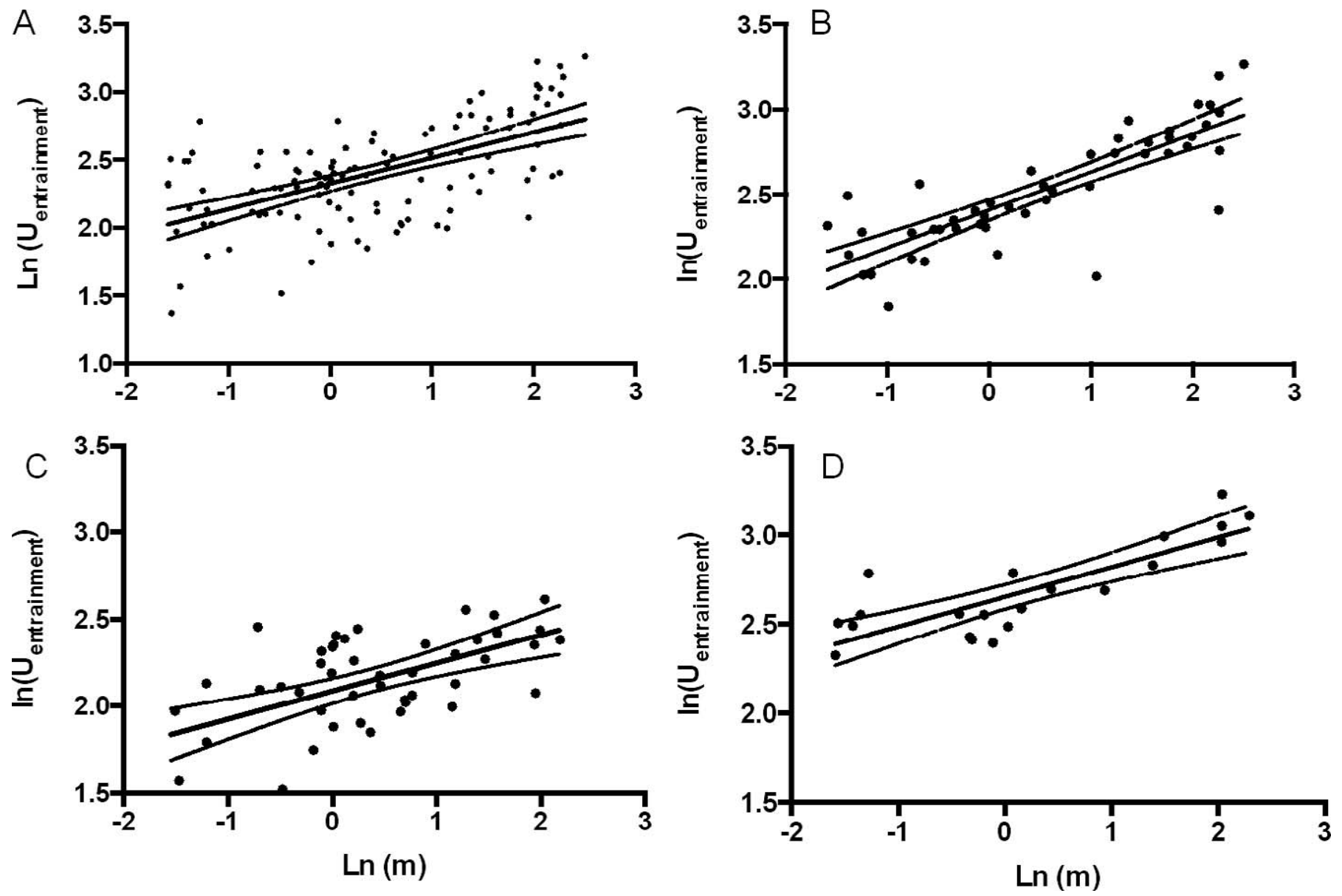

FIG. 4. - Entrainment velocity $\left(U_{\text {entrainment }} ; \mathrm{cm} / \mathrm{s}\right)$ as a function of shell mass $(m ; \mathrm{g})$. A) All shells, including drilled and undrilled $(\mathrm{N}=115)$. B) Undrilled shells $(\mathrm{N}=$ 48). C) Umbonally drilled shells $(\mathrm{N}=46)$. D) Centrally drilled shells $(\mathrm{N}=21)$. In each figure, the thick solid line is the best-fit line to the data and the dashed lighter lines represent $95 \% \mathrm{CI}$. The equation of the best-fit line in area $\mathrm{A}$ is $\ln U=2.33+0.19 \ln m\left(R^{2}=0.35\right)$, in area $\mathrm{B}$ is $\ln U=2.41+0.22 \ln m\left(R^{2}=0.68\right)$; in area $\mathrm{C}$ is $\ln U=2.09$ $+0.16 \ln m\left(R^{2}=0.34\right)$, in area $\mathrm{D}$ is $\ln U=2.65+0.17 \ln m\left(R^{2}=0.68\right)$. 


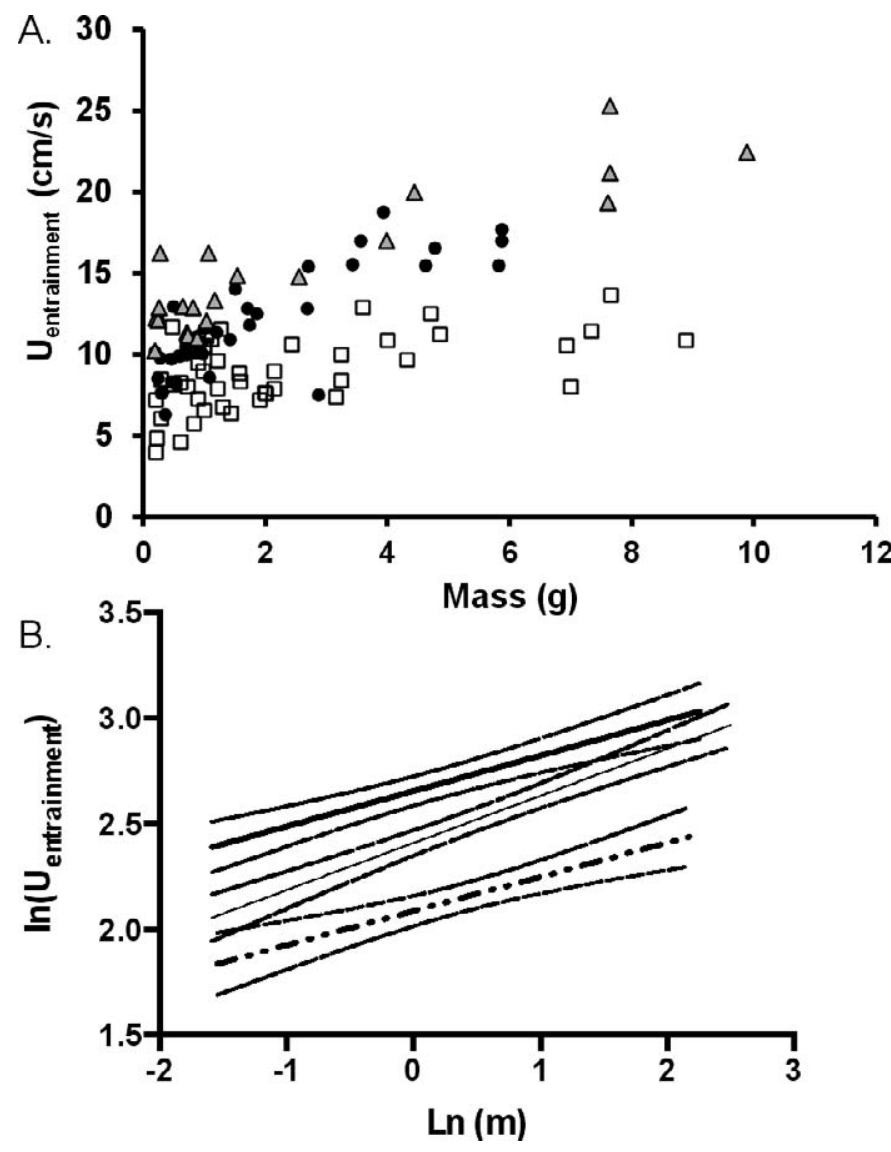

FIG. 5.-A) Entrainment velocity $\left(U_{\text {entrainment }} ; \mathrm{cm} / \mathrm{s}\right)$ as a function of shell mass $(m ; \mathrm{g})$ for all shells. Open square $=$ umbonally drilled shells, solid circle $=$ undrilled shell, cross $=$ centrally drilled shells. B) A $\ln -\ln$ plot of entrainment velocity $\left(U_{\text {entrainment }} ; \mathrm{cm} / \mathrm{s}\right)$ as a function of shell mass $(m ; \mathrm{g})$ for all shells. Solid lines are the best-fit lines to the data and dashed lines represent 95\% CI. Best-fit lines are as in Figure 4, but with data points removed.

that the $\log -\log$ best-fit lines have equivalent slopes. The intercepts, however, differ significantly $\left(H_{0}: a_{\text {undrilled }}=a_{\text {umbonal }}=a_{\text {central }} ; \mathrm{p}<\right.$ $0.0001 ; F$-test) with the centrally drilled shells having the highest intercept $\left(a_{\text {central }}=2.65 \pm 0.07\right)$, the umbonally drilled shells the lowest $\left(a_{\text {umbonal }}=\right.$ $2.09 \pm 0.08)$, and undrilled shells intermediate $\left(a_{\text {undrilled }}=2.41 \pm 0.06\right)$, making the overall relationship between mass and EV significantly different for the three categories of shells ( $p<0.0001$; ANCOVA).

\section{Effect of Drill-Hole Position}

A significantly different relationship between mass and EV characterizes shells drilled centrally and those drilled umbonally. Shells of equal mass that are drilled centrally require a significantly higher EV than shells drilled umbonally (Fig. 5).

\section{Result of Simulation}

We plotted the data with increasing FV and corresponding values of DF, mean prey size, variance in prey size, and DS (Fig. 6A-D). Each graph presents the value of one such variable at different $\mathrm{FV}$ for three categories: transported, lag, and original. The result of the comparison is presented in Table 2. For both of the altered categories (transported and lag), the average value of the parameter is significantly different from the original (Table 2). At low velocities, the lag assemblage is comparable to the original one for all the parameters. The same is true for the transported assemblage in the highest velocity zone (Fig. 6).

\section{DISCUSSION}

\section{Factors Affecting Entrainment}

The threshold current velocity for the entrainment of an undrilled convex-up shell is significantly lower than for a centrally drilled shell. This confirms our theoretical prediction about the effect of the hole on lift. Lift is caused by a pressure gradient between the inside and outside of the shell. According to Bernoulli's principle, as fluid moves over the outside of the shell, streamlines become compressed over its most elevated portion, producing a zone of high velocity and low pressure. Since water inside the shell remains stationary, the pressure inside the shell is high (Fig. 1A); thus an upward pressure (lift) acts on the shell. In the presence of a hole on the elevated part of the shell (with planar cross section aligned parallel to the streamlines), the pressure gradient developed between the inside and outside of the shell causes water to move through the drill hole from the inside to the outside; as a result the pressure difference is less for a centrally drilled than an undrilled shell (Fig. 1B). Such pressure leakage has been confirmed by using dye in an experiment conducted on drilled specimens of Mulinia lateralis (Chattopadhyay 2009).

This mechanism is not applicable to umbonally drilled shells. With the umbo oriented upstream, the position of the hole is close to the medium, and its planar cross section is nearly perpendicular to the approaching streamlines. Since the compression of streamlines in this region does not occur, the pressure gradient that exists over the top of the shell is not developed in this location. Furthermore, the oncoming streamlines strike the hole perpendicular to its cross sectional area, and the inertia of the fluid may be sufficient for the fluid to enter the shell. This has been observed in a dye experiment conducted on M. lateralis by Chattopadhyay (2009), who noted that the water enters the umbonally drilled shells through the drill hole and creates a vortex. Dye inside the shell is quickly dispersed, and its residence time is short. In contrast, dye inside a centrally drilled shell takes longer to dissipate. This suggests that for umbonally drilled shells, fluid enters the shell through the hole more rapidly and that its momentum adds an additional component of drag on the shell as the fluid is rapidly decelerated inside the shell, somewhat analogous to the effect on drag of ducts, diffusers, and radiators (Hoerner 1965).

As a consequence, the presence of an umbonally located hole leads to a decrease in EV (Savory and Toy 1986; Manhart 1998) (Fig. 1C). This observation is consistent with the findings of Lever et al. (1961), who found a significant contrast in the abundance of umbonally drilled and undrilled shells between the top and the base of a beach slope in a mark and recapture experiment with different genera of bivalves. They found that umbonally drilled shells were preferentially carried to the top of the slope and explained this as a consequence of their lower entrainment velocities. Their observations of umbonally drilled shells suggest a mechanism similar to the one in our experiments. Although we have used a glass bottom that does not represent the natural sedimentary beds, it was confirmed that even with sediments the basic pattern remains the same (Lever et al. 1961; Miller 1991). The velocities recorded in this experiment are quite similar to characteristic velocities in low-energy shallow marine shelf systems (Harms 1979).

\section{Effect of Transportation on an Assemblage}

Postmortem transportation is significantly dependent on aspects of the morphology of shells (including drilled shells) and could lead to assemblages that are quite different from the original population as demonstrated by the simulation. In the simplest scenario, the effect of 

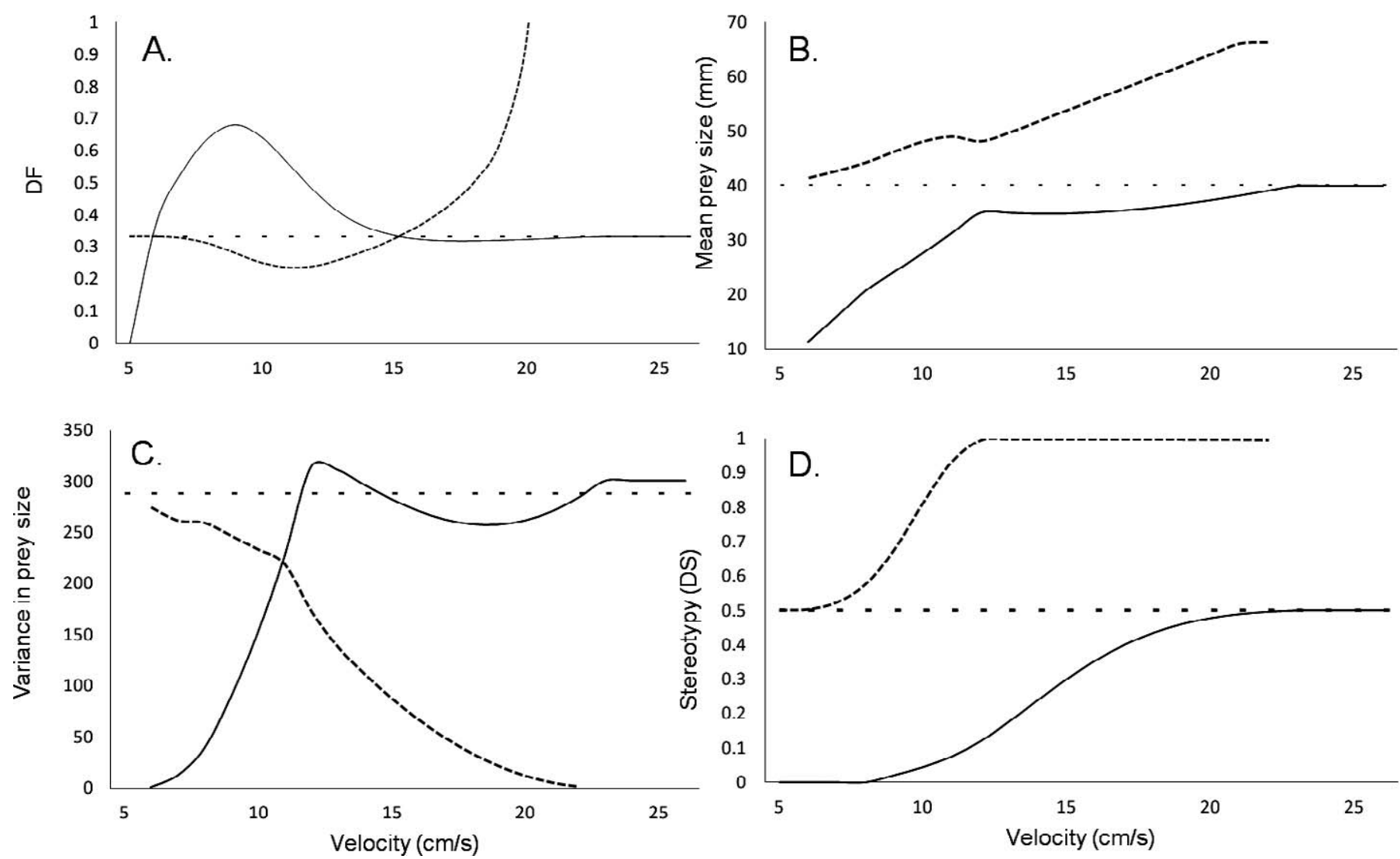

FIG. 6. - The effect of velocity on various parameters. Solid gray line $=$ transported assemblage, dotted gray line $=$ lag assemblage, black dots $=$ true value. A) The relationship between velocity and drilling frequency. B) The relationship between velocity and mean size of drilled shell. C) The relationship between velocity and variance in size of drilled shell. D) The relationship between velocity and site stereotypy of drilled shell.

differential transport could be manifested in two ways and therefore create two different types of altered assemblages: (1) transported assemblage, composed of the shells transported from an original assemblage, and (2) lag assemblage, composed of the shells that were left behind during transportation. Although both depend on the nature of the fluid flow, the final configuration of these individual assemblages could be far from identical. Even though we would expect some combination of the two in the natural world, we will look at the patterns in those two discrete assemblages to avoid complication.

Effect on Drilling Frequency.-The frequency of drilled shells in the assemblage is commonly reported as a measure of intensity of gastropod drilling predation (see Kelley and Hansen 2003, for a review). Such data have been used to identify preferred prey taxa (Kitchell et al. 1981; Hoffman and Martinell 1984) and changes in predator-prey interactions through time (Vermeij 1983, 1987; Kelley 1989, 1991). Long-term changes in drilling frequencies reflect the changing mode of predation in benthic marine communities (Vermeij 1987; Kelley and Hansen 1993, 1996, 2006; Harper 2006 for a review). Our experiment shows that hydrodynamic differences could lead to preferential loss of particular classes (drilled or undrilled). Our simulation result demonstrates that the calculated predation intensity in a hydrodynamically altered assemblage will be greatly different from the original one (Fig. 6A; Table 2).

Different taxa of bivalves within a given assemblage could suffer varying degrees of transport because shell transport varies as a function of size, shape, and mass. High variances observed in the proportion of drilled individuals among species and localities (Vermeij 1980; Anderson 1992) may possibly reflect differential transport rather than (or in addition to) biotic signals. The extent of transportation bias for each taxon should be estimated individually before intraspecific comparisons of predation intensities are undertaken. The relationship between predation intensity and velocity might affect local fossil assemblages; however, it is unlikely to be responsible for long-term global trends in drilling frequency (Vermeij 1987; Kowalewski et al. 1998) because on those time scales the changes in velocity should be randomly distributed.

Effect on Prey Size Selectivity.-Drilling predators do not attack their prey randomly; rather they choose their prey to maximize the net energy gain (e.g., Kitchell et al. 1981; Chattopadhyay and Baumiller 2009). Such selectivity often results in the existence of a preferred prey size group. Our

TABLE 2.-Average difference between original and altered assemblages for various parameters.

\begin{tabular}{|c|c|c|c|c|c|c|c|c|}
\hline & \multicolumn{2}{|c|}{ Drilling frequency (DF) } & \multicolumn{2}{|c|}{ Mean prey size } & \multicolumn{2}{|c|}{ Variance in prey size } & \multicolumn{2}{|c|}{ Stereotypy (DS) } \\
\hline & $t$ & $p$ & $t$ & $p$ & $t$ & $p$ & $t$ & $p$ \\
\hline Transported assemblage & 2.829 & 0.01 & -4.307 & 0.0004 & -2.676 & 0.01 & -4.389 & 0.0007 \\
\hline Lag assemblage & 2.733 & 0.01 & 6.629 & $<0.00001$ & -6.41 & $<0.00001$ & 8.391 & $<0.00001$ \\
\hline
\end{tabular}


simulation results indicate that the average size of the targeted prey groups could substantially change in hydrodynamically altered assemblages (Fig. 6B; Table 2). Often the variation in the drilled valve size is used as a proxy to document selectivity: low variance in prey size indicates a high level of selectivity by the predator if the drill-hole size remains constant (Kelley and Hansen 2003). With the help of our simulation result, we have demonstrated that the variance in size of prey is also likely to change in hydrodynamically altered assemblages (Fig. 6C; Table 2). Such alteration could easily be misdiagnosed as prey preference or lack thereof in recent and fossil assemblages.

Effect on Site Stereotypy.-Earlier studies on drill-hole site selectivity have emphasized the biological implication of such stereotypy. Site selectivity has been related to the way predators manipulate a prey item (Ziegelmeier 1954), size and shape of the prey (e.g., Ansell 1960; Stump 1975; Kitchell 1986; Reyment 1999; Roopnarine and Willard 2001), ontogenetic growth (e.g., Vignali and Galleni 1986; Calvet 1992), and access to particular soft parts (e.g., Hughes and Dunkin 1984; Arua and Haque 1989; Leighton 2001). Site selectivity has also been used to show trends in predatory behavior through time (Roopnarine and Willard 2001). The results of the experiment and simulation indicate that in different velocities drilled shells will be sorted according to the position of the drill hole and thereby create different proportions of central to umbonally drilled shells. In a low-velocity flow, we can expect to see a selective entrainment of umbonally drilled shells among the drilled ones. The transported assemblage will have a highly skewed distribution of drilled shells with the majority of umbonally drilled shells and, as a result, the lag assemblage will have a higher proportion of centrally drilled individuals left behind by the low-velocity flow (Fig. 6D). Such sorting might lead us to misdiagnose the identity of the predator. Some muricids can produce holes with morphologies similar to those of naticids (Kelley and Hansen 2003); however, they often show a significant difference in drill-hole placement. For instance, Chione from sea grass beds in Florida are drilled by naticids at the umbo and muricids in the center of the valve (PH Kelley, personal communication, 2013). In such cases, the assemblages would be sorted by the responsible predator due to site stereotypy. Identification of a specific gastropod as the predator is therefore possible, while the real prey assemblage was shared among two different types of predatory gastropods. In an environment where the average velocity is higher than the velocity needed to move centrally drilled shells, we might not see a very pronounced bias because everything will be transported. If, however, the settling velocities differ for drilled and undrilled shells because velocity will ultimately decrease and shells will settle, then the effect of hydrodynamic sorting even in a high-energy environment might be seen.

\section{Assessment of Biases}

Our results demonstrate that recognition of postmortem transportation is important in studies of drilling predation. Inferred drilling frequency, preferred prey size, and the pattern of drill-hole position (and therefore inferred stereotypic behavior) could be influenced by hydrodynamic sorting. It is therefore important to ensure that an assemblage had not experienced transport if one wants to use such frequency data. Identifying assemblages that may have experienced some transport is possible by relying on a few relatively robust indicators, and when these are found, a potential for bias cannot be ignored.

Among indicators of an assemblage having been subjected to hydrodynamic forces are such sedimentary features as imbricated grains, preferentially aligned shells, and ripple marks (Reineck and Singh 1975). If an assemblage is associated with such features, the shells most likely experienced hydrodynamic forces as well and caution is warranted. Of course, even such indicators can be obscured, for example, through extensive bioturbation. Right-left valve ratios can also provide insights to the hydrodynamic history of an assemblage. Strongly unequal numbers of right and left valves in an assemblage are indicative of hydrodynamic sorting (Martin-Kaye 1951; Boucot et al. 1958; Lever 1958; Kornicker et al. 1963; Chattopadhyay et al. 2013). Similarly, if the calculated value of drilling frequency exceeds $100 \%$ (Kowalewski 2002), the original assemblage has been altered.

A similar approach could be used to identify a bias in a drilled assemblage. The same range of current velocities will be capable of transporting a wider size range of the former than of the latter, because umbonally drilled shells have a lower entrainment velocity than undrilled shells. As a consequence, a transported assemblage will consist of a broader range of sizes of umbonally drilled shells than of undrilled shells. In such an assemblage, the undrilled size range would be a subset of the drilled size range, whereas biotic interactions typically produce the opposite pattern: a predator selects a particular size class from a broad range of possible prey. Thus, if undrilled shell sizes are but a subset of drilled shell sizes, the assemblage is likely to have been subjected to hydrodynamic forces.

Finally, one trend that could rule out the effect of hydrodynamic bias would be a systematic nonrandom signal in drilling frequency and/or stereotypy. In a spatial or temporal series, the time averaging of hydrodynamic biases could mask the original biotic signals, but time averaging alone is unlikely to generate a persistent temporal or spatial trend. So if the study of time-averaged samples reveals a temporal trend, then most likely it is indicating a true biotic signal, not a hydrodynamic artifact. Clearly, caution must be exercised when studying specimens from single time units (event beds for instance), because hydrodynamic sorting could have greatly altered the assemblage in terms of drilling frequency and stereotypy.

\section{CONCLUSIONS}

Drill holes in the shells of invertebrates represent one of the most unambiguous signatures of predator-prey interactions and have been commonly used by neontologists and paleontologists to explore ecological and evolutionary questions. A relatively smaller number of studies, however, have looked at the potential taphonomic biases affecting the record of drilling predation. Here, we discussed one such taphonomic bias, namely, hydrodynamic sorting. Using disarticulated specimens of $D$. scortum, we experimentally determined the entrainment velocities of both drilled and undrilled valves. The results of the flow-tank experiment clearly demonstrate that the size of shell plays an important role in the movement of both drilled and undrilled shells. Results also show a significant difference in entrainment velocity between drilled and undrilled shells: an undrilled shell has a significantly lower entrainment velocity compared with a centrally drilled shell. Surprisingly, an undrilled shell has a significantly higher entrainment velocity than an umbonally drilled shell.

We also demonstrate the extent of alteration of an assemblage by this bias through a computer simulation based on the experimental results. The simulation demonstrates that this hydrodynamic transport can dramatically alter drilling intensity, size, and patterns of stereotypy. Recognition of assemblages that have experienced transport is, therefore, extremely important, and we proposed some general criteria to help identify such assemblages. If evidence of transport can be found, it may be safer to exclude such assemblages from the quantitative analysis of drilling frequencies and patterns. More work is needed to explore whether, and how, hydrodynamic bias affects other taxa. For instance, given the morphological differences between bivalves and gastropods (Statzner and Holm 1989), the two groups are unlikely to be affected in the same way. The same could be factual for organisms of very different sizes, for example, those that are relatively small, such as ostracodes, 
foraminifera, serpulid worms (e.g., Kontrovitz 1975; Kontrovitz et al. 1978; Kontrovitz and Snyder 1981; Klompmaker 2012; Martinell et al. 2012). Also, this study was restricted to experiments conducted in unidirectional flow, while most of the shallow marine areas experience oscillatory flow. The Bernoulli mechanism should apply under oscillatory flow as well, and this has been confirmed by wave-tank experiments and field observations. The detailed nature of the biases, however, may indeed be different under oscillatory flow regimes, and that should be explored.

\section{ACKNOWLEDGMENTS}

We thank B.S. Mazumder, in charge of Fluvial Mechanics Laboratory, Indian Statistical Institute, Calcutta, for providing access to the experimental facility, and K. Das, D.K. Pal, and H. Maity for ADV assistance. A. Das, P.P. Saha, and S. Dutta have made valuable contributions in primary data acquisition, and D. Sarkar helped with the photograph. We also thank Martin Aberhan, Tricia Kelley, and an anonymous reviewer for their helpful comments. The project has been funded by IISER Kolkata (Indian Institute of Science Education and Research, Kolkata) through Summer Project Fellowship, MS-Dissertation Fellowship, and Professional Development Allowance.

\section{REFERENCES}

AleXander, R.R., 1975, Phenotypic liability of the brachiopod Rafinesquina alternata (Ordovician) and its correlation with the sedimentologic regime: Journal of Paleontology, v. 49, p. 607-610.

Alexander, R.R., 1984, Comparative hydrodynamic stability of brachiopod shells on current-scoured arenaceous substrates: Lethaia, v. 17, p. 17-32.

AleXANDER, R.R., 1986, Life orientation and post-mortem reorientation of Chesterian brachiopod shells by paleocurrents: PALAIOS, v. 1, p. 303-311.

Allen, J.R.L., 1984, Experiments on the settling, overturning and entrainment of bivalve shells and related models: Sedimentology, v. 31, p. 227-250.

Anderson, L.C., 1992, Naticid gastropod predation on corbulid bivalves: Effects of physical factors, morphological features and statistical artifacts: PALAIOS, v. 7, p. 602-617.

Ansell, A.D., 1960, Observations on predation of Venus striatula (Da Costa) by Natica alderi (Forbes): Proceedings of the Malacological Society of London, v. 34, p. 248 249.

Arua, I., AND Haque, M., 1989, Predatory gastropod boreholes in an Eocene molluscan assemblage from Nigeria: Lethaia, v. 22, p. 49-52.

Behrens, E.W., and Watson, R.L., 1969, Differential sorting of pelecypod valves in the swash zone: Journal of Sedimentary Petrography, v. 39, p. 159-165.

Boucot, A.J., 1953, Life and death assemblages among fossils: American Journal of Science, v. 251, p. 25-40.

Boucot, A.J., Brace, W., and Demar, R., 1958, Distribution of Brachiopod and Pelecypod shells by current: Journal of Sedimentary Petrology, v. 28, p. 321-332.

Brenchley, P.J., and Newall, G., 1970, Flume experiments on the orientation and transport of models and shell valves: Palaeogeography, Palaeoclimatology, Palaeoecology, v. 7, p. 185-220.

CAlvet, C., 1992, Borehole site-selection in Naticarius hebraeus (Chemnitz in Karsten, 1769) (Naticidae: Gastropoda)?: Orsis, v. 7, p. 57-64.

Carriker, M.R., and Yochelson, E.L., 1968, Recent gastropod boreholes and Ordovician cylindrical borings: U.S. Geological Survey, Professional Paper, v. 593B, p. 1-26.

Chattopadhyay, D., 2009, Predation in Molluscs: A Multi-Taxon Approach Using Neontological and Paleontological Data: ProQuest, UMI Dissertation Publishing, Ann Arbor, Michigan, 174 p.

Chattopadhyay, D., 2011, First evidence of predatory drilling from Upper Cretaceous Eutaw formation (Santonian), Georgia: Southeastern Geology, v. 48, p. 37-44.

Chattopadhyay, D., and Baumiller, T.K., 2009, An experimental assessment of feeding rates of the muricid gastropod Nucella lamellosa and its effect on a costbenefit analysis: Journal of Shellfish Research, v. 28, p. 883-889.

Chattopadhyay, D., and Dutta, S., 2013, Prey selection by drilling predators: A case study from Miocene of Kutch, India: Palaeogeography, Palaeoclimatology, Palaeoecology, v. 374, p. 187-196.

Chattopadhyay, D., Miller, D.J., and Baumiller, T.K., 2006, Hydrodynamic effects of drill holes on post-mortem transport of bivalve shells: Geological Society of America, Abstracts with Programs, v. 38, p. 442.

Chattopadhyay, D., Rathie, A., and Das, A., 2013, The effect of morphology on postmortem transportation of bivalve and its taphonomic implications: PALAIOS, v. 28, p. 203-209.

Christensen, B.A., 1981, On the risk of erosion of cohesionless sea floors: Oceans, v. 13, p. 706-714.

De Cauwer, G., 1985, Gastropod predation on corbulid bivalves-palaeoecology or taphonomy? Annales de la Societe royale zoologique de Belgique, v. 115, p. 183-196.
DEY, S., 2003, Incipient motion of bivalve shells on sand beds under flowing water: Journal of Engineering Mechanics, v. 129, p. 232-240.

FreY, R.W., AND DörJes, J., 1988, Fair and foul weather shell accumulations on a Georgia beach: PALAIOS, v. 3, p. 561-576.

Frey, R.W., AND Henderson, S.W., 1987, Left-right phenomena among bivalve shells: Examples from the Georgia coast: Senckenbergiana Maritima, v. 19, p. 223-247.

FUTTERER, E., 1982, Experiments on the distinction of wave and current influenced shell accumulations, in Seilacher, A., ed., Cyclic and Event Stratification: Springer-Verlag, Berlin, p. 175-179.

Hagstrom, K.M., 1996, Effects of compaction and wave-induced forces on the preservation and macroevolutionary perception on Naticid predator-prey interactions [unpublished MS thesis]: Indiana University, Bloomington, Indiana, $225 \mathrm{p}$.

Hammer, Ø., Harper, D.A.T., and Ryan, P.D., 2001, PAST: Paleontological Statistics Software Package for Education and Data Analysis: Palaeontologia Electronica, 4,178 kb, http://palaeo-electronica.org/2001_1/past/issue1_01.htm. Accessed March 4, 2014

Harms, J.C., 1979, Primary sedimentary structures: Annual Review of Earth and Planetary Sciences, v. 7, p. 227-248.

Harper, E.M., 2006, Dissecting post-Palaeozoic arms races: Palaeogeography, Palaeoclimatology, Palaeoecology, v. 232, p. 322-343.

Harper, E.M., Forsythe, G.T.W., and Palmer, T., 1998, Taphonomy and the Mesozoic marine revolution: Preservation state masks the importance of boring predators: PALAIOS, v. 13 , p. $352-360$.

Hoerner, S.F., 1965, Fluid-Dynamic Drag: Practical Information on Aerodynamic Drag and Hydrodynamic Resistance, 2nd ed.: Hoerner Fluid Dynamics, Bricktown, New Jersey, 598 p.

Hoerner, S.F., 1992, Fluid-Dynamic Drag: Theoretical, Experimental and Statistical Information: Hoerner Fluid Dynamics, Vancouver, Washington.

Hoffman, A., 1976, Mortality patterns of some bivalves from the Badenian (Miocene) Korytnica Clays, Poland: Neues Jahrbuch für Geologie und Paläontologie: Monatshefte, v. 1976, p. 337-349.

Hoffman, A., And Martinell, J., 1984, Prey selection by naticid gastropods in the Pliocene of Emporda (Northeast Spain). Neues Jahrbuch für Geologie und Paläontologie: Monatshefte, v. 1984, p. 393-399.

Hoffman, A., Pisera, A., And Ryszkiewicz, M., 1974, Predation by muricid and naticid gastropods on the lower Tortonian mollusks from the Korytnica Clays: Acta Geologica Polonica, v. 24, p. 249-260.

Hughes, R.N., And Dunkin, S.D., 1984, Behavioral components of prey selection by dogwhelks Nucella lapillus feeding on mussels Mytilus edulis in the laboratory: Journal of Experimental Marine Biology and Ecology, v. 77, p. 45-68.

JoHnson, R.G., 1958, Experiments on the burial of shells: Journal of Geology, v. 65, p. $527-535$

Kabat, A.R., And Kohn, A.J., 1986, Predation on early Pleistocene naticid gastropods in Fiji: Palaeogeography, Palaeoclimatology, Palaeoecology, v. 53, p. 255-269.

Kaplan, P., AND Baumiller, T.K., 2000, Taphonomic inferences on boring habit in the Richmondian Onniella meeki Epibole: PALAIOS, v. 15, p. 499-510.

Kardon, G., 1998, Evidence from the fossil record of an antipredatory exaptation: Conchiolin layers in corbulid bivalves: Evolution, v. 52, p. 68-79.

Kelley, P.H., 1982, Prey preference of naticid gastropods of the Chesapeake Group: Taxonomic and stratigraphic patterns: Geological Society of America, Abstracts with Programs, v. 14, p. 527.

Kelley, P.H., 1988, Predation by Miocene gastropods of the Chesapeake Group: Stereotyped and predictable: PALAIOS, v. 3, p. 436-448.

Kelley, P.H., 1989, Evolutionary trends within bivalve prey of Chesapeake Group naticid gastropods: Historical Biology, v. 2, p. 139-156.

Kelley, P.H., 1991, The effect of predation intensity on rate of evolution of five Miocene bivalves: Historical Biology, v. 5, p. 65-88.

Kelley, P.H., 2008, Role of bioerosion in taphonomy: Effect of predatory drillholes on preservation of mollusc shells, in Wisshak, M., and Tapanila, L., eds., Current Developments in Bioerosion: Springer-Verlag, Berlin, p. 451-470.

Kelley, P.H., And Hansen, T.A., 1993, Evolution of the naticid gastropod predatorprey system: An evaluation of the hypothesis of escalation: PALAIOS, v. 8, p. 358375 .

Kelley, P.H., AND Hansen, T.A., 1996, Naticid gastropod prey selectivity through time and the hypothesis of escalation: PALAIOS, v. 11, p. 437-445.

Kelley, P.H., and Hansen, T.A., 2003, The fossil record of drilling predation on bivalves and gastropods, in Kelley, P.H., Kowalewski, M., and Hansen, T.A., eds., Predator-Prey Interactions in the Fossil Record: Kluwer Academic/Plenum Press, New York, p. 113-139.

Kelley, P.H., and Hansen, T.A., 2006, Comparisons of class-and lower taxon-level patterns in naticid gastropod predation, Cretaceous to Pleistocene of the US Coastal Plain: Palaeogeography, Palaeoclimatology, Palaeoecology, v. 236, p. 302-320.

Kitchell, J.A., 1986, The evolution of predator-prey behavior: Naticid gastropods and their molluscan prey, in Nitecki, M.H., and Kitchell, J.A., eds., Evolution of Anima Behavior: Paleontological and Field Approaches: Oxford University Press, New York, p. 88-110.

Kitchell, J.A., Boggs, C.H., Kitchell, J.F., And Rice, J.A., 1981, Prey selection by naticid gastropods: Experimental tests and application to the fossil record: Paleobiology, v. 7, p. 533-552.

Klompmaker, A.A., 2009, Taphonomic bias on drill-hole predation intensities and paleoecology of Pliocene mollusks from Langenboom (Mill), The Netherlands: PALAIOS, v. 24, p. 772-779. 
Klompmaker, A.A., 2012, Drill hole predation on fossil serpulid polychaetes, with new data from the Pliocene of the Netherlands: Palaeogeography, Palaeoclimatology, Palaeoecology, v. 321, p. 113-120.

Kontrovitz, M., 1975, A study of the differential transportation of ostracodes: Journal of Paleontology, v. 49, p. 937-941.

Kontrovitz, M., and SNYder, S.W., 1981, Reliability of microfossil assemblages as paleoenvironmental indicators: Transactions, Gulf Coast Association of Geological Societies, v. 31, p. 323-324.

Kontrovitz, M., SNyder, S.W., And Brown, R.J., 1978, A flume study of the movement of the foraminifera tests: Paleogeography, Paleoclimatology, Paleoecology, v. 23, p. $141-150$.

Kornicker, L.S., AND ARmstrong, N., 1959, Mobility of partially submerged shells: Institute of Marine Science Publication, v. 6, p. 171-185.

KorNICKER, L.S., Wise, C.D., AND WISE, J.M., 1963, Factors affecting the distribution of opposing mollusk valves: Journal of Sedimentary Petrology, v. 33, p. 703-712.

Kowalewski, M., 2002, The fossil record of predation: An overview of analytical methods: Paleontological Society, Papers, v. 8, p. 3-42.

Kowalewski, M., Dulai, A., and Fürsich, F.T., 1998, A fossil record full of holes: The Phanerozoic history of drilling predation: Geology, v. 26, p. 1091-1094.

LABARBERA, M., 1977, Brachiopod orientation to water movement: Theory, laboratory behavior and field orientations: Paleobiology, v. 3, p. 270-287.

Leighton, L., 2001, Evaluating the accuracy of drilling frequency as an estimate of prey preference and predation intensity: PaleoBios, v. 22, p. 83.

LEVER, J., 1958, Quantitative beach research I. The "left-right phenomenon": Sorting of lamellibranch valves on sandy beaches: Basteria, v. 22, p. 21-51.

Lever, J., Kessler, A., Van Over Beeke, P., and Thijssen, R., 1961, Quantitative beach research II, The "hole effect": A second mode of sorting of lamellibranch valves on sandy beaches: Netherlands Journal of Sea Research, v. 1, p. 339-358.

Lever, J., AND Thisssen, R., 1968, Sorting phenomena during the transport of shel valves on sandy beaches studied with the use of artificial valves, in Fretter, V., ed., Studies in the Structure, Physiology, and Ecology of Molluscs: Symposia of the Zoological Society of London, v. 22, p. 259-271.

MANHART, M., 1998, Vortex shedding from a hemisphere in a turbulent boundary layer: Theoretical and Computational Fluid Dynamics, v. 12, p. 1-28.

Martinell, J., Kowalewski, M., And Domènech, R., 2012, Drilling Predation on Serpulid Polychaetes (Ditrupa arietina) from the Pliocene of the Cope Basin, Murcia Region, Southeastern Spain: PloS One, v. 7, p. e34576.

Martin-KAYE, P., 1951, Sorting of lamellibranch valves on beaches in Trinidad: B.W.I Geological Magazine, v. 88, p. 432-434.

Mazumder, B.S., RaY, R.N., and Dalal, D.C., 2005, Size distributions of suspended particles in open-channel flow over sediment beds: Environmetrics, v. 16, p. 149-165.

MCKitTrick, M.A., 1987, Experiments on the settling of gastropod and bivalve shells: Biostratinomic implications, in Flessa, K.W., ed., Paleoecology and Taphonomy of Recent to Pleistocene Intertidal Deposits, Gulf of California: Special Publication 2, Paleontological Society, p. 150-163.

Menard, H.W., AND Boucot, A.J., 1951, Experiments on the movement of shells by water: American Journal of Science, v. 249, p. 131-151.

Messina, C., And Labarbera, M., 2004, Hydrodynamic behavior of brachiopod shells: Experimental estimates and field observations: PALAIOS, v. 19, p. 441-450.

MiLleR, D.J., 1991, Hydrodynamic behavior of drilled and undrilled bivalve shells: Potential sources of taphonomic bias: Geological Society of America, Abstracts with Programs, v. 23, p. A458.

Nagle, J.S., 1964, Differential sorting of shells in the swash zone: Biological Bulletin, v. 127 , p. 353.

NAGLe, J.S., 1967, Wave and current orientation of shells: Journal of Sedimentary Petrology, v. 37, p. 1124-1138

Olivera, A.M., AND Wood, W.L., 1997, Hydrodynamics of bivalve shell entrainment and transport: Journal of Sedimentary Research, v. 67, p. 514-526.

Pena, E., Anta, J., Puertas, J., And Teijeiro, T., 2008, Estimation of drag coefficient and settling velocity of the Cockle Cerastoderma edule using particle image velocimetry (PIV): Journal of Coastal Research, v. 4, p. 150-158.

Quaresma, V.S., Amos, C.L., And Bastos, A.C., 2007, The influence of articulated and disarticulated cockle shells on the erosion of a cohesive bed: Journal of Coastal Research, v. 23, p. 1143-1451.
Reineck, H.E., AND Singh, I.B., 1975, Depositional Sedimentary Environments: Springer-Verlag, Berlin, 549 p.

Reyment, R., 1999, Drilling gastropods, in E. Savazzi, ed., Functional Morphology of the Invertebrate Skeleton: John Wiley and Sons, New York, p. 197-204.

Roopnarine, P.D., and Willard, S., 2001, Bivalve prey morphology as a guide to drilling stereotypy of naticid and muricid gastropods: Venerids, naticids and muricids in Tropical America: PaleoBios, v. 2, p. 109-110.

Roy, K., Miller, D.J., and Labarbera, M., 1994, Taphonomic bias in analysis of drilling predation: Effects of gastropod drill holes on bivalve shell strength: PALAIOS, v. 9, p. 413-421.

SAVARESE, M., 1994, Taphonomic implications of flow-induced forces on concavoconvex articulate brachiopods: An experimental approach: Lethaia, v. 27, p. 301-312.

SAVORY, E., AND Toy, N., 1986, The flow regime in the turbulent near wake of a hemisphere: Experiments in Fluids, v. 4, p. 181-188.

Stanton, R.J., JR., and Nelson, P.C., 1980, Reconstruction of the trophic web in paleontology: Community structure in the Stone City Formation (middle Eocene, Texas): Journal of Paleontology, v. 54, p. 118-135.

Statzner, B., AND Holm, T.F., 1989, Morphological adaptation of shape to flow: Microcurrents around lotic macroinvertebrates with known Reynolds numbers at quasi-natural flow conditions: Oecologia, v. 78, p. 145-157.

Stump, T.E., 1975, Pleistocene molluscan paleoecology and community structure of the Puerto Libertad region, Sonora, Mexico: Paleogeography, Paleoclimatology, Paleoecology, v. 17, p. 177-226.

TAYLOR, J.D., 1970, Feeding habits of predatory gastropods in a Tertiary (Eocene) molluscan assemblage from the Paris basin: Palaeontology, v. 23, p. 254-260.

Taylor, J.D., Cleevely, R.J., ANd Morris, N.J., 1983, Predatory gastropods and their activities in the Blackdown Greensand (Albian) of England: Palaeontology, v. 26, p. 521-553.

TELford, M., 1981, A hydrodynamic interpretation of sand dollar morphology: Bulletin of Marine Science, v. 31, p. 605-622.

Telford, M., 1983, An experimental analysis of lunule function in the sand dollar Mellita quinquiesperforata. Marine Biology, v. 76, p. 125-134.

Trewin, N.H., AND Welsh, W., 1972, Transport, breakage and sorting of the bivalve Mactra corallina on Aberdeen beach, Scotland: Palaeogeography, Palaeoclimatology, Palaeoecology, v. 12, p. 193-204.

Velbel, M.A., AND BRANDT, D.S., 1989, Differential preservation of brachiopod valves: Taphonomic bias in Platystrophia ponderosa. PALAIOS, v. 4, p. 193-195.

VermeIJ, G.J., 1980, Drilling predation of bivalves in Guam: Some paleoecological considerations: Malacologia, v. 19, p. 329-334.

Vermeis, G.J., 1983, Traces and trends of predation with special reference to bivalved animals: Palaeontology, v. 26, p. 455-465.

Vermeis, G.J., 1987, Evolution and Escalation: an Ecological History of Life: Princeton University Press, Princeton, New Jersey, $557 \mathrm{p}$.

VermeiJ, G.J., AND Dudley, E.C., 1982, Shell repair and drilling in some gastropods from the Ripley Formation (Upper Cretaceous) of Southeastern U.S.A. Cretaceous Research, v. 3, p. 397-403.

Vermeis, G.J., Dudley, E.C., AND Zipser, E., 1989, Successful and unsuccessful drilling in recent pelecypods: The Veliger, v. 32, p. 266-273.

Vermeis, G.J., Zipser, E., AND Dudley, E.C., 1980, Predation in time and space: Drilling in terebrid gastropods: Paleobiology, v. 6, p. 352-364.

Vignali, R., AND Galleni, L., 1986, Naticid predation on soft bottom bivalves: A study on a beach shell assemblage: Oebalia, v. 13, p. 157-178.

Vogel, S., 1994, Life in Moving Fluids: Princeton University Press, Princeton, New Jersey, $467 \mathrm{p}$.

ZiegelmeIR, E., 1954, Beobachtungen uber den Nahrungserwerb bei der Naticide Lunatia nitida Donovan (Gastropoda Prosobranchia): Helgolander Wissenschaftliche Meeresforschung, v. 5, p. 1-3.

Zuschin, M., AND Stanton, R.J., JR., 2001, Experimental measurement of shell strength and its taphonomic interpretation: PALAIOS, v. 16, p. 161-170.

Received 18 March 2013; accepted 28 September 2013. 